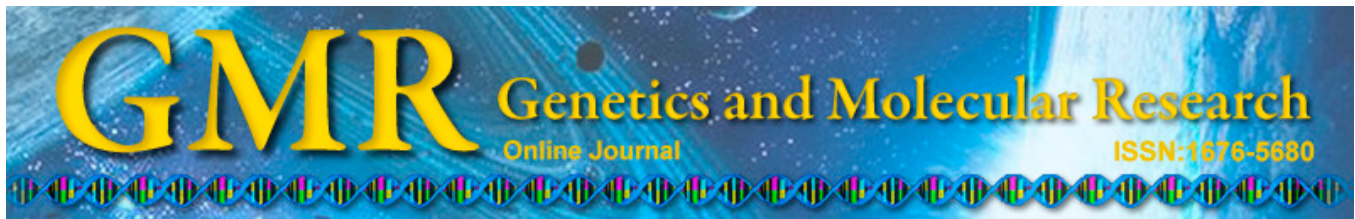

\title{
Assessment of correlation between pre-miRNA-1757 polymorphism and chicken performance traits
}

\author{
H. Li, K.R. Jiang, S.H. Wang, X.J. Liu, X.T. Kang, R.R. Jiang, \\ Z.J. Li and G.R. Sun \\ College of Animal Science and Veterinary Medicine, \\ Henan Agricultural University, Henan Innovative Engineering Research \\ Center of Poultry Germplasm Resource, Zhengzhou, China \\ Corresponding author: G.R. Sun \\ E-mail: grsun2000@126.com
}

Genet. Mol. Res. 14 (4): 12184-12195 (2015)

Received March 30, 2015

Accepted June 8, 2015

Published October 9, 2015

DOI http://dx.doi.org/10.4238/2015.October.9.7

\begin{abstract}
Single nucleotide polymorphism in microRNAs (miRNA) may influence their target gene selection and regulation efficiency, leading to animal phenotypic variation. The aim of this study was to evaluate the possible effect of single nucleotide polymorphisms in the miRNA-1757 gene precursor region (pre-mir-1757) on economicrelated traits in chicken. Genotyping was performed using Sequenom MassArray ${ }^{\circledR}$ iPLEX GOLD System. Association analysis was performed using SPSS19.0. The data showed that the $\mathrm{G} / \mathrm{C}$ polymorphism was significantly correlated with semi-evisceration weight, evisceration weight, carcass weight, body weight at 10 weeks of age, shank length at 4 weeks of age, pectoral angle at 8 weeks of age, and body slanting length and pelvis breadth at 12 weeks of age $(\mathrm{P}<0.05)$, and led to the alteration of the RNA secondary structure of pre-mir-1757. Our results provide useful information for further annotation studies of miRNA function.
\end{abstract}

Key words: Chicken; Function annotation; miRNA-1757; Target gene; Polymorphisms 


\section{INTRODUCTION}

Understanding the basis of animal genetic variations is a major task in breeding research. Various phenotypic traits are related to changes in gene sequences caused by different types of polymorphisms and mutations, which can alter protein structure and function. Among these variants, attention has recently been focused on single nucleotide polymorphisms (SNPs). Many SNPs that do not occur in protein-coding regions may still influence biological processes, such as transcription factor binding, gene splicing, and messenger degradation

MicroRNAs (miRNAs) as a class of non-coding RNAs and are reportedly involved in a broad range of biological processes, such as embryonic development (Mei et al., 2014), cellular differentiation (Tang et al., 2014), proliferation (Hou et al., 2012), apoptosis (Ferreira et al., 2014), cancer development (Liao et al., 2014), and insulin secretion (Locke et al., 2014). Limited functional studies have implicated miRNAs in muscle development and hypertrophy, adipose tissue growth, oocyte maturation, and early embryonic development in farm animals (Wang et al., 2013). SNPs occurring within miRNAs are likely to result in phenotypic differences, can alter protein secondary structure, and therefore affect production traits and susceptibility to diseases by affecting miRNA maturation, functional strand selection, and target binding site (Georges et al., 2007; Gong et al., 2012). An increasing number of studies have suggested that SNPs in miRNAs are associated with variations in production performance or health traits in farm animals. A polymorphism residing within gga-miR-1657 was found to be associated with growth and meat quality traits in chicken (Li et al., 2012). SNPs in the porcine miR-206/miR$133 \mathrm{~b}$ cluster have been found to be genetic factors affecting muscle and meat quality traits (Lee et al., 2013). These studies suggest a greater role of genomic variations in modulating miRNA function and regulation, manifesting as phenotypic correlates (Sun et al., 2009).

In recent years, most miRNA-related studies have focused on humans and mammals, showing important roles in diseases and development, among other factors. Although numerous novel miRNAs were identified in chicken, functional studies remain limited. Based on our previous bioinformatic analysis, SNPs in the miR-1757 precursor region led to alterations in the secondary structure of miRNA precursors. The miR-1757 gene as an intronic miRNA is located in intron 1 of the solute carrier (SLC) family 25A member 43 (SLC25A43) host gene on chromosome 4. SLC25A43 encodes for a mitochondrial transport protein, and may be involved in cell turnover, metabolism, and cell proliferation (Lindqvist et al., 2012, Tina et al., 2012). Intronic miRNAs have been reported to play an antagonistic or synergetic role with their host genes (Gao et al., 2012). Elucidation of the role of intronic miRNAs will increase the understanding of host gene expression and intron function.

Because of the presently available evidence for polymorphic miRNA-mediated gene regulation and its effect on phenotypic variation and disease, we examined the effect of SNPs in $m i R-1757$. In this study, we determined the association between polymorphisms in miRNA and chicken economic traits.

\section{MATERIAL AND METHODS}

\section{Study animals and DNA extraction}

A Gushi-Anka $\mathrm{F}_{2}$ resource population as previously described (Han et al., 2012; Li et al., 2012) was used as the experiment material. The population was a cross of a slow-growing 
Chinese native chicken breed Gushi chicken and a fast-growing broiler Anka chicken. The $24 \mathrm{~F}_{0}$ Gushi hens mated with $4 \mathrm{~F}_{0}$ Anka roosters, and $12 \mathrm{~F}_{0}$ Anka hens mated with $2 \mathrm{~F}_{0}$ Gushi roosters to generate $7 \mathrm{~F}_{1}$ families. The $860 \mathrm{~F}_{2}$ birds were produced in 2 hatch interval of 2 weeks by intercrossing $7 \mathrm{~F}_{1}$ roosters with $63 \mathrm{~F}_{1}$ hens. All $\mathrm{F}_{2}$ chickens were housed in cages under the same environmental conditions with ad libitum access to feed and water, and fed according to National Research Council (1994) recommendations. Each chicken was weighed every 2 weeks from hatch until to slaughter, and body size indices such as shank girth, shank length, chest depth, breastbone length, chest breadth, pelvis breadth, pectoral angle, and body slanting length were measured every 4 weeks from hatch. At 12 weeks of age, all chickens were slaughtered. Blood samples were taken from the jugular vein of each chicken. Carcass traits including carcass weight, semi-evisceration weight (SEW, carcass weight excluding the trachea, esophagus, crop, intestine, spleen, pancreas, gallbladder, and reproductive organs), evisceration weight (SEW excluding the heart, liver, proventriculus, gizzard, head, feet, and abdominal fat), breast muscle weight, leg weight, and leg muscle weight were measured and recorded ( $\mathrm{Li}$ et al., 2013). DNA extraction from the blood samples was carried out using standard phenol-chloroform method. Because the DNA was used for matrix-assisted laser desorption/ionization-time-of-flight mass spectrometry (MS) genotyping, all DNA samples were diluted to a working concentration and stored at $-80^{\circ} \mathrm{C}$.

\section{Secondary structure prediction}

To evaluate the effect of different alleles on the secondary structure of the miRNA precursor, the M-fold (Zuker, 2003) software was used to calculate the most stable secondary RNA structure with the lowest free energy for pre-mir-1757. The complete difference in the free energy with different alleles was used as the parameter to evaluate the impact on the secondary structure of pre-mir-1757.

\section{SNP detection}

One hundred DNA samples with same concentration and equal amount from the $\mathrm{F}_{2}$ resource population were selected randomly to construct a DNA pool. A pair of polymerase chain reaction (PCR) primers containing the precursor of the miR-1757 gene sequence (GenBank accession No. MI0007499) was designed according to the public chicken genome sequence (NR_035258.1). The PCR product was purified using a kit (Tiangen Biotech Co., Ltd., Beijing, $\bar{C}$ hina), and sequenced by Sangon Biotech Co., Ltd. (Shanghai, China) to scan SNPs in the miR-1757 precursor region (Zorc et al., 2012).

\section{Pre-miR-1757 polymorphism genotyping using matrix-assisted laser desorption/ ionization-time-of-flight MS}

\section{PCR amplification}

SNP genotyping was performed using the MassARRAY system (Sequenom) according to manufacturer instructions (Cerezo et al., 2009; Thorleifsson et al., 2010; Mendisco et al., 2011), and were analyzed with the SpectroTYPER RT 2.0 software (Sequenom, Inc., San 
Diego, CA, USA). For the rs15505339 SNP, amplification primers and an extension primer were designed using the Assay Design 3.1 software (Sequenom). The 1st PCR primer sequence was 5'-ACGTTGGATGCAAAGGGAGCCGACAGAATC-3'; the 2nd PCR primer sequence was 5'-ACGTTGGATGTCTGGTCCGCTGTTTAGTTC-3', and the extension primer was 5'-GAACAGTAGGTTTCTGTTCTT-3'. PCR amplifications were carried out in a 5- $\mu \mathrm{L}$ reaction volume containing $0.625 \mu \mathrm{L} \mathrm{10X}$ buffer, $0.1 \mu \mathrm{L} 5 \mathrm{U} / \mu \mathrm{L}$ HotStar Taq, $0.1 \mu \mathrm{L} 25 \mathrm{mM}$ dNTPs, $1 \mu \mathrm{L} 500 \mathrm{nM}$ primer mix, and $0.325 \mu \mathrm{L} 25 \mathrm{nM} \mathrm{MgCl}_{2}$. The PCR procedure was $95^{\circ} \mathrm{C}$ for $2 \mathrm{~min}$, followed by 45 cycles at $95^{\circ} \mathrm{C}$ for $30 \mathrm{~s}, 56^{\circ} \mathrm{C}$ for $30 \mathrm{~s}, 72^{\circ} \mathrm{C}$ for $60 \mathrm{~s}$, and $72^{\circ} \mathrm{C}$ extension for $5 \mathrm{~min}$.

\section{Shrimp alkaline phosphatase (SAP) treatment}

To digest the unincorporated dNTPs, SAP treatment was carried out after PCR amplification. To the PCR products, $2 \mu \mathrm{L}$ SAP solution containing $0.3 \mu \mathrm{L} 1 \mathrm{U} / \mu \mathrm{L}$ SAP and $0.17 \mu \mathrm{L}$ 10X SAP buffer was added and incubated at $37^{\circ} \mathrm{C}$ for $40 \mathrm{~min}$ and $85^{\circ} \mathrm{C}$ for $5 \mathrm{~min}$, and then stored at $4^{\circ} \mathrm{C}$.

\section{Single-base extension reaction}

The single-base extension reactions were performed by adding $2 \mu \mathrm{L}$ iPLEX Gold cocktail mix (Sequenom). The following reaction procedure was used: $94^{\circ} \mathrm{C}$ for $30 \mathrm{~s}$, followed by 40 cycles at $94^{\circ} \mathrm{C}$ for $5 \mathrm{~s}, 52^{\circ} \mathrm{C}$ for $5 \mathrm{~s}$, and $80^{\circ} \mathrm{C}$ for $5 \mathrm{~s}$ with 5 internal cycles, $72^{\circ} \mathrm{C}$ extension for $3 \mathrm{~min}$, and cooling to $4^{\circ} \mathrm{C}$. The iPLEX Gold reaction products were desalted by adding $16 \mu \mathrm{L}$ water and $6 \mathrm{mg}$ resin (SpectroCLEAN, Sequenom, Inc.) to optimize mass-spectrometric analysis according to the protocol developed by Sequenom.

\section{Matrix-assisted laser desorption/ionization-time-of-flight MS analysis}

The prepared extended products were arrayed onto a SpectroCHIP. The products were detected using a MassARRAY mass spectrometer. Related data including the call rate and peak area were acquired using the software provided by the manufacturer. Alleles were automatically assigned by the software.

\section{Target bioinformatic analysis}

To evaluate the biological function of $m i R-1757$, predicted targets were identified using miRDB (http://mirdb.org/miRDB/) and TargetScan Human6.2 (http://www.targetscan. org/) online softwares. Pathway and Gene Ontology (GO)-enrichment analysis were performed to the predicted target genes using DAVID Bioinformatics Resources 6.7 (http://david. abcc.ncifcrf.gov/home.jsp).

\section{Statistical analysis}

The population genetic characteristics of $m i R-1757$ SNP were calculated using the Excel program. Correlation between the polymorphism and chicken growth characteristics 
was analyzed using the linear mixed model I of SPSS 19.0 (SPSS, Inc., Chicago, IL, USA). Considering the effect of body weight on carcass traits, the relationship between polymorphisms and carcass traits was assessed using the linear mixed model II. A P value $<0.05$ was considered to be statistically significant, and the Benferroni test was performed to control multiple comparisons.

$$
\text { Model I: } \mathrm{Y}_{\mathrm{ijklm}}=\mu+\mathrm{G}_{\mathrm{i}}+\mathrm{S}_{\mathrm{j}}+\mathrm{H}_{\mathrm{k}}+\mathrm{f}_{1}+\mathrm{e}_{\mathrm{ijk} k \mathrm{~m}}
$$

Model II: $\mathrm{Y}_{\mathrm{ijklm}}=\mu+\mathrm{G}_{\mathrm{i}}+\mathrm{S}_{\mathrm{j}}+\mathrm{H}_{\mathrm{k}}+\mathrm{f}_{1}+\mathrm{b}\left(\mathrm{W}_{\mathrm{ijklm}}{ }^{-}\right)+\mathrm{e}_{\mathrm{ijklm}}$, and the average carcass weight.

where $Y_{\mathrm{ijklm}}$ represents the observation; $\mu$ the overall mean, $\mathrm{G}_{\mathrm{i}}$ the fixed effect of genotype ( $\mathrm{i}$ $=\mathrm{CC}, \mathrm{CG}, \mathrm{gG}) ; \mathrm{f}_{1}$ the random effect of family $(1=7) ; \mathrm{S}_{\mathrm{j}}$ the fixed effect of $\operatorname{sex}(\mathrm{j}=\mathrm{f}, \mathrm{m}), \mathrm{H}_{\mathrm{k}}$ the fixed effect of hatch $(\mathrm{k}=2)$, and $\mathrm{e}_{\mathrm{ijklm}}$ the random error. $\mathrm{b}$ is the regression coefficient for carcass weight; $\mathrm{W}_{\mathrm{ijklm}}$ the individual carcass weight; $\mathrm{W}_{\mathrm{ijklm}}$ the average carcass weight.

\section{RESULTS}

\section{Identification of pre-mir-1757 gene polymorphism and genotyping}

According to the sequencing results, g.90 G>C rs15505339 was found to exist in the precursor region of $m i R-1757$ in the population as previously published (http://www. integratomics-time.com/miRNA-SNiPer/); detailed information is shown in Figure 1. The SNP was genotyped using the MassARRAY system. The mass spectrogram of variant genotypes is summarized in Figures 2 and 3. The frequencies of the rs 15505339 for CC, CG, and GG genotypes were $3.2,83.1$, and $13.7 \%$. The loci polymorphic information content of $m i R-1757$ rs 15505339 in the $\mathrm{F}_{2}$ resource population was 0.372 , while the values for heterozygosity and effective number of alleles were 0.494 and 1.978, respectively. The frequencies of premir- $1757+90 \mathrm{G}>\mathrm{C}$ in the population were consistent with Hardy-Weinberg equilibrium.

\begin{tabular}{|c|c|c|c|c|}
\hline miRNA name & miRNA & mature miRNA & variation & details \\
\hline gga-mir-1757 & $\begin{array}{l}\text { Gallus gallus } \\
4: 16712627- \\
\underline{16712731[-]}\end{array}$ & $\begin{array}{l}\text { gga-miR-1757 } \\
\text { Mature: } 16712652-16712672 \\
\text { Seed: } 16712665-16712671 \text { from TargetScan } \\
\text { GCUGUUUUGCCGUGGAUGAACAAAACUCUUCUGG } \\
\text { UCCGCUGUUUAGUUCAAUUAGCGCUUCAGAGG } \\
\text { CGGAACAGUAGGUUUCUGUUCUUCCAGCCAAG } \\
\text { AUUCUGU }\end{array}$ & rs15505339 & $\begin{array}{l}\text { In pre-mature } \\
16712642 \\
\text { SNP }(G>C)\end{array}$ \\
\hline
\end{tabular}

Figure 1. Detailed information of variant in the miR-1757 gene. Bases are colored sky blue for seed region, and bases in color for mature miRNA region, base in yellow shadow for mutation site.

\section{Effect of pre-mir-1757 SNP on chicken growth and carcass traits}

The correlation between pre-mir-1757 SNP genotypes and chicken growth (Table 1) and carcass traits (Table 2) is respectively shown. A remarkable association between premir-1757 SNP genotype and carcass traits was observed. Values for carcass weight, SEW, and evisceration weight in individuals with the GG and CG genotype were higher than in those 
with the CC genotype. The P values for leg weight and leg muscle weight traits were nearly significant. The results showed that the SNP was significantly related to body weight at 10 weeks of age, shank length at 4 weeks of age, pectoral angle at 8 weeks of age, body slanting length at 12 weeks of age, and pelvis breadth at 12 weeks of age $(\mathrm{P}<0.05)$, and the related body size indices were lower in individuals carrying the GG genotype than in those with the $\mathrm{CC}$ and CG genotype. Values for shank length at 8 weeks and chest breadth at 12 weeks of age were almost significant.

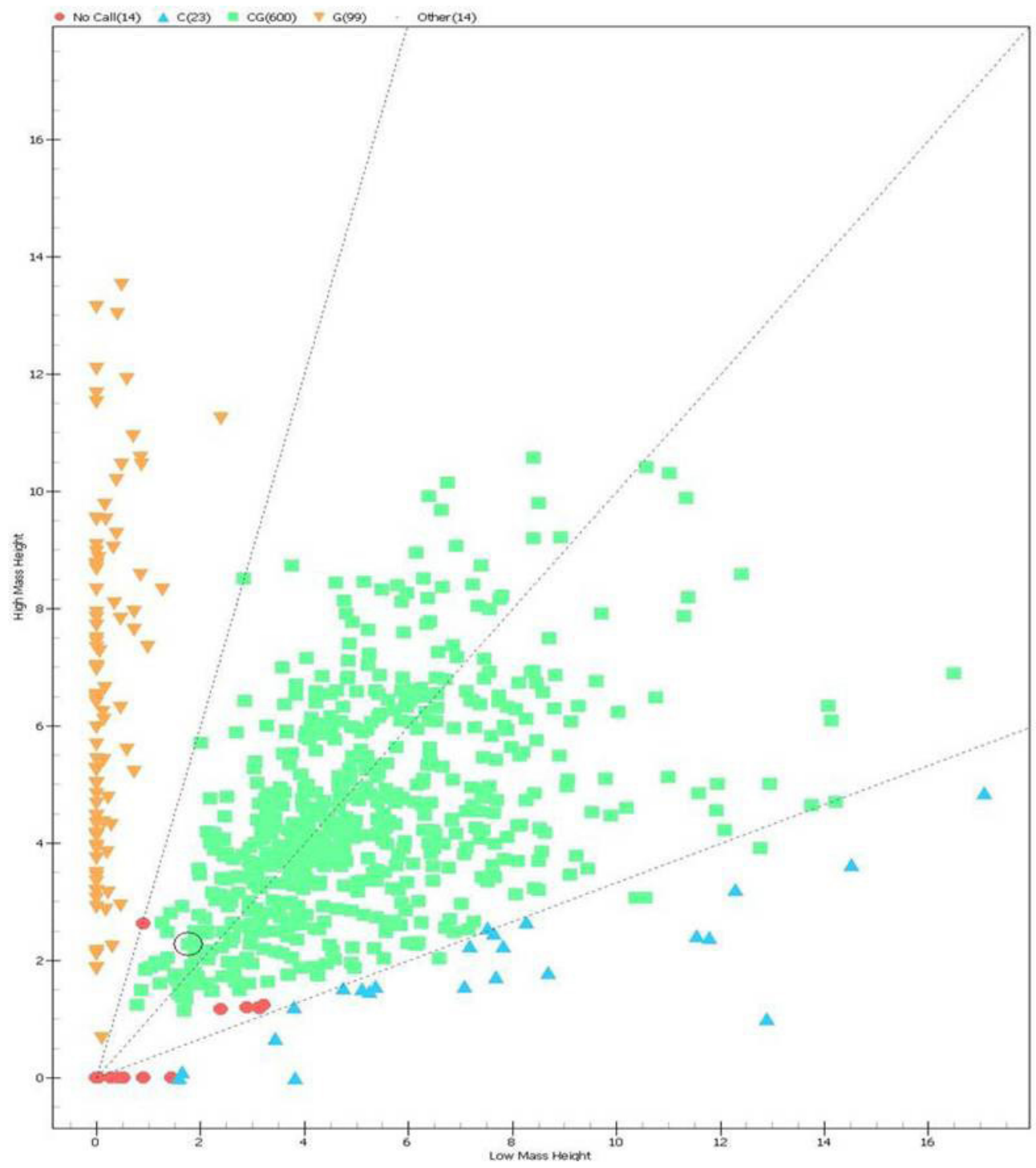

Figure 2. Genotyping calls for variants at pre-mir-1757 in a 384-plate of samples: samples carrying C allele are indicated by a blue triangle while those carrying $\mathrm{G}$ are displayed as yellow triangle, and those carrying $\mathrm{CG}$ are displayed by a green square. 


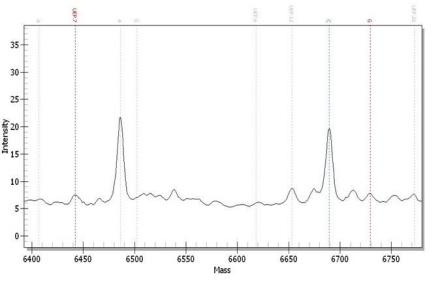

CC genotype

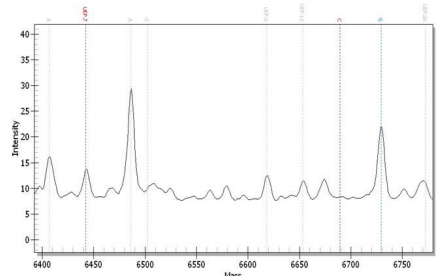

GG genotype

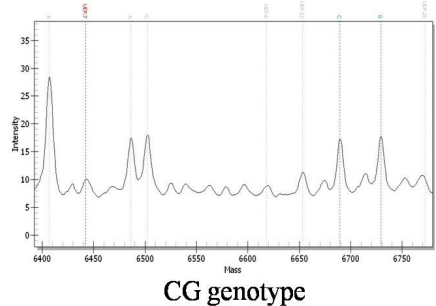

Figure 3. Mass spectrogram of the CC, CG, and GG polymorphisms of G/C in pre-mir-1757.

Table 1. Association between pre-miR-1757 G>C +90 polymorphism and chicken growth traits.

\begin{tabular}{|c|c|c|c|c|}
\hline \multirow[t]{2}{*}{ Growth traits } & \multicolumn{3}{|c|}{ Means $\pm \mathrm{SE}$} & \multirow[t]{2}{*}{$P$ value } \\
\hline & $\mathrm{CC}$ & CG & GG & \\
\hline BW0 (g) & $31.04 \pm 0.73$ & $30.78 \pm 0.44$ & $30.42 \pm 0.52$ & 0.496 \\
\hline BW2 (g) & $125.11 \pm 5.20$ & $122.37 \pm 2.78$ & $117.61 \pm 3.48$ & 0.112 \\
\hline BW4 (g) & $316.53 \pm 13.39$ & $320.26 \pm 7.76$ & $314.20 \pm 9.25$ & 0.540 \\
\hline BW6 (g) & $529.41 \pm 23.45$ & $562.09 \pm 13.78$ & $547.88 \pm 16.63$ & 0.105 \\
\hline BW8 (g) & $805.71 \pm 35.51$ & $813.37 \pm 19.79$ & $787.32 \pm 24.42$ & 0.266 \\
\hline BW10 (g) & $1059.73 \pm 44.26^{\mathrm{ab}}$ & $1117.27 \pm 25.48^{\mathrm{a}}$ & $1056.03 \pm 30.85^{b}$ & 0.010 \\
\hline BW12 (g) & $1314.93 \pm 50.44$ & $1353.62 \pm 27.18$ & $1312.23 \pm 34.25$ & 0.149 \\
\hline $\mathrm{SL0}(\mathrm{cm})$ & $2.58 \pm 0.02$ & $2.58 \pm 0.01$ & $2.56 \pm 0.01$ & 0.229 \\
\hline $\mathrm{SL} 4(\mathrm{~cm})$ & $5.56 \pm 0.19^{\mathrm{ab}}$ & $5.51 \pm 0.07^{\mathrm{a}}$ & $5.26 \pm 0.11^{\mathrm{b}}$ & 0.029 \\
\hline SL8 (cm) & $7.56 \pm 0.16$ & $7.92 \pm 0.05$ & $7.85 \pm 0.09$ & 0.056 \\
\hline SL12 (cm) & $9.13 \pm 0.15$ & $9.40 \pm 0.06$ & $9.34 \pm 0.09$ & 0.127 \\
\hline $\mathrm{SG} 4(\mathrm{~cm})$ & $2.71 \pm 0.06$ & $2.69 \pm 0.03$ & $2.68 \pm 0.04$ & 0.802 \\
\hline SG8 (cm) & $3.40 \pm 0.06$ & $3.41 \pm 0.03$ & $3.41 \pm 0.04$ & 0.939 \\
\hline SG12 (cm) & $3.77 \pm 0.06$ & $3.84 \pm 0.02$ & $3.81 \pm 0.04$ & 0.293 \\
\hline $\mathrm{CD} 4(\mathrm{~cm})$ & $4.68 \pm 0.15$ & $4.85 \pm 0.03$ & $4.75 \pm 0.07$ & 0.245 \\
\hline CD8 (cm) & $6.52 \pm 0.21$ & $6.51 \pm 0.05$ & $6.58 \pm 0.11$ & 0.843 \\
\hline CD12 (cm) & $7.79 \pm 0.19$ & $7.88 \pm 0.05$ & $7.80 \pm 0.10$ & 0.656 \\
\hline CB4 (cm) & $4.08 \pm 0.12$ & $4.10 \pm 0.03$ & $4.05 \pm 0.06$ & 0.691 \\
\hline CB8 (cm) & $5.56 \pm 0.14$ & $5.68 \pm 0.04$ & $5.61 \pm 0.07$ & 0.439 \\
\hline $\mathrm{CB} 12(\mathrm{~cm})$ & $6.28 \pm 0.16$ & $6.35 \pm 0.07$ & $6.18 \pm 0.10$ & 0.090 \\
\hline BBL4 (cm) & $6.18 \pm 0.14$ & $6.21 \pm 0.06$ & $6.22 \pm 0.08$ & 0.958 \\
\hline BBL8 (cm) & $8.91 \pm 0.17$ & $8.91 \pm 0.07$ & $8.85 \pm 0.10$ & 0.829 \\
\hline $\operatorname{BBL} 12(\mathrm{~cm})$ & $10.93 \pm 0.18$ & $10.99 \pm 0.08$ & $10.82 \pm 0.11$ & 0.142 \\
\hline PA4 $\left(^{\circ}\right)$ & $73.51 \pm 0.98$ & $74.37 \pm 0.24$ & $73.41 \pm 0.49$ & 0.103 \\
\hline PA8 $\left(^{\circ}\right)$ & $77.91 \pm 1.26^{\mathrm{ab}}$ & $76.60 \pm 0.44^{\mathrm{a}}$ & $74.83 \pm 0.71^{\mathrm{b}}$ & 0.012 \\
\hline $\operatorname{PA} 12\left({ }^{\circ}\right)$ & $79.92 \pm 1.05$ & $79.14 \pm 0.43$ & $78.62 \pm 0.63$ & 0.448 \\
\hline BSL4 (cm) & $11.39 \pm 0.22$ & $11.37 \pm 0.10$ & $11.35 \pm 0.13$ & 0.974 \\
\hline BSL8 (cm) & $16.10 \pm 0.27$ & $16.25 \pm 0.08$ & $16.08 \pm 0.14$ & 0.380 \\
\hline BSL12 $(\mathrm{cm})$ & $19.61 \pm 0.26^{\mathrm{ab}}$ & $19.80 \pm 0.10^{\mathrm{a}}$ & $19.43 \pm 0.16^{\mathrm{b}}$ & 0.019 \\
\hline PB4 (cm) & $5.22 \pm 0.12$ & $5.15 \pm 0.04$ & $5.07 \pm 0.06$ & 0.337 \\
\hline PB8 (cm) & $6.71 \pm 0.16$ & $6.88 \pm 0.05$ & $6.77 \pm 0.09$ & 0.247 \\
\hline $\mathrm{PB} 12(\mathrm{~cm})$ & $8.33 \pm 0.19^{\mathrm{ab}}$ & $8.72 \pm 0.04^{\mathrm{a}}$ & $8.47 \pm 0.09^{b}$ & 0.008 \\
\hline
\end{tabular}

Means in the same line with different superscripts are significantly different at $\mathrm{P}<0.05$. $\mathrm{BW}=$ body weight at 0 day, $2,4,6,8,10$, and 12 weeks; $\mathrm{SL}=$ shank length at 4,8 , and 12 weeks; $\mathrm{SG}=$ shank girth at 4,8 , and 12 weeks; $\mathrm{CD}=$ chest depth at 4,8 , and 12 weeks; $\mathrm{CB}=$ chest breadth at 4,8 , and 12 weeks; $\mathrm{BBL}=$ breast bone length at 4,8 , and 12 weeks; $\mathrm{PA}=$ pectoral angle at 4,8 , and 12 weeks; $\mathrm{BSL}=$ body slanting length at 4,8 , and 12 weeks; $\mathrm{PB}=$ pelvis breadth at 4,8 , and 12 weeks. 
Table 2. Association between pre-miR-1757 G>C +90 polymorphism and chicken carcass traits.

\begin{tabular}{lcccr}
\hline Carcass traits & \multicolumn{3}{c}{ Means \pm SE } & P value \\
\cline { 2 - 4 } & CC & CG & GG & \\
\hline CW $(\mathrm{g})$ & $1131.97 \pm 45.13$ & $1191.32 \pm 25.27$ & $1145.70 \pm 31.19$ & 0.029 \\
SEW (g) & $1044.99 \pm 44.07$ & $1105.17 \pm 25.20$ & $1061.88 \pm 30.49$ & 0.024 \\
EW (g) & $878.28 \pm 38.82$ & $922.69 \pm 23.07$ & $884.81 \pm 27.43$ & 0.032 \\
BMW (g) & $65.90 \pm 4.42$ & $70.50 \pm 2.61$ & $67.30 \pm 3.08$ & 0.108 \\
LW (g) & $143.44 \pm 6.80$ & $149.52 \pm 4.14$ & $143.12 \pm 4.87$ & 0.051 \\
LMW (g) & $95.04 \pm 5.00$ & $99.34 \pm 3.04$ & $95.09 \pm 3.61$ & 0.089 \\
\hline
\end{tabular}

$\mathrm{CW}=$ carcass weight; $\mathrm{SEW}=$ semi-evisceration weight; $\mathrm{EW}=$ evisceration weight; $\mathrm{BMW}=$ breast muscle weight; LW = leg weight; LMW = leg muscle weight.

\section{Secondary structure alterations of variant pre-mir-1757}

The result predicted by the $\mathrm{M}$-fold (Zuker, 2003) program showed that the $\mathrm{G}>\mathrm{C}$ variant located in the precursor region of $m i R-1757$ introduced a base-pairing mismatch, altering the free energy values. The alleles of rs 15505339 led to a precursor structure of miR-1757 with new RNA bulges, as shown in Figure 4.
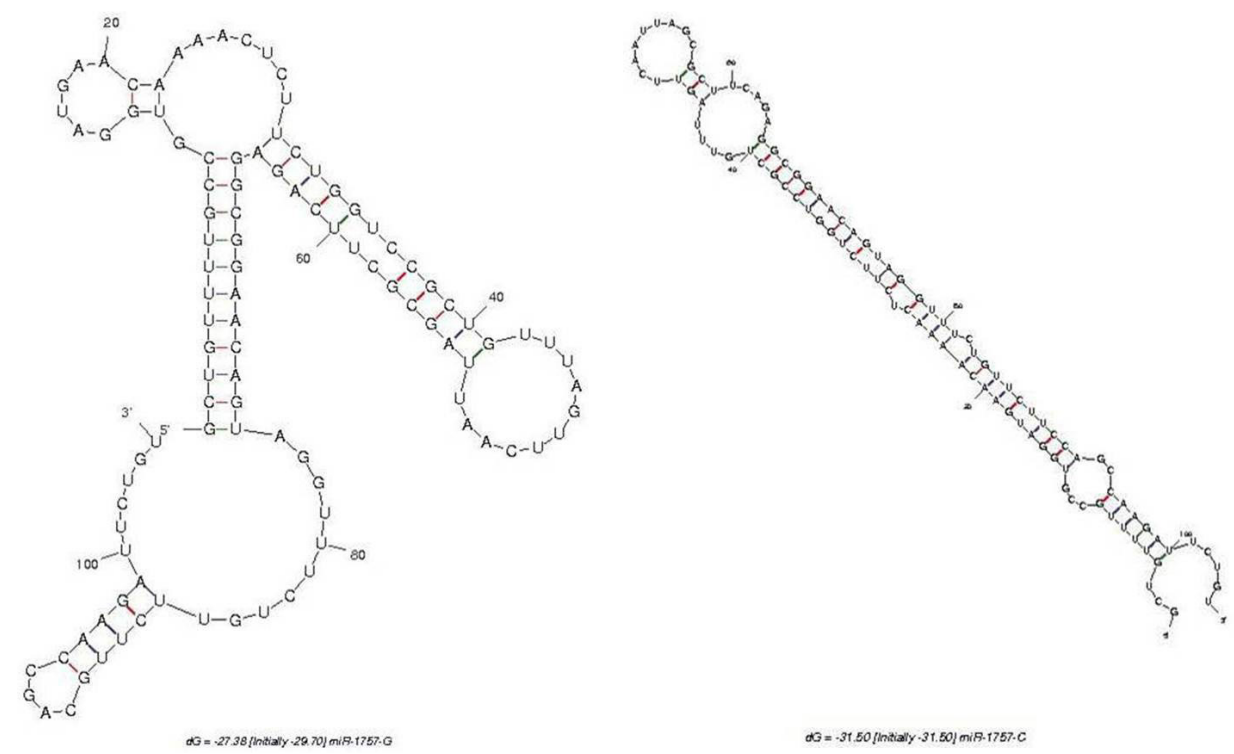

Figure 4. Predicted secondary structure of the pre-mir-1757 with different alleles.

\section{Putative target bioinformatic analysis}

A total of 170 genes potentially targeted by $m i R-1757$ were predicted using miRDB and the TargetScan software. GO category analysis showed that the predicted miR-1757 target genes were mainly enriched in transcription factor binding, cellular process, regulation of biological process, metabolic process, multicellular organism process, and developmental process (Figure 5). 


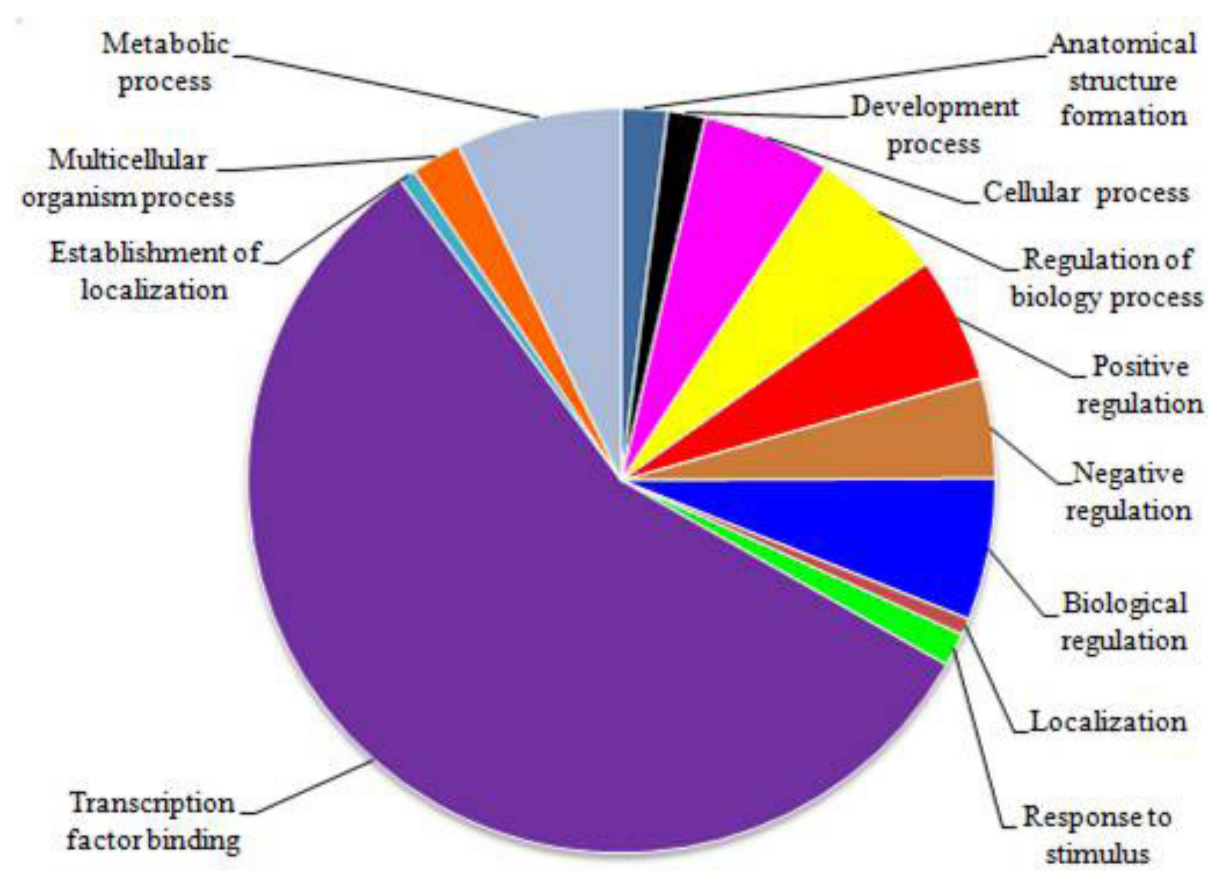

Figure 5. Pie chart shows functional pattern analysis (Gene Ontology) of the targets.

\section{DISCUSSION}

Sequence variations within miRNA genes may alter various biological processes by influencing the processing and/or target selection of miRNA (Duan et al., 2007). SNPs within miRNA present a source of novel biomarkers for phenotypic traits in animal breeding. In this study, we found that the pre-mir-1757 rs15505339 G/C polymorphism might be related to chicken carcass traits. Compared with the $\mathrm{C}$ allele, chickens carrying the $\mathrm{G}$ allele are heavier in carcass weight, SEW, and evisceration weight. The SNP was also associated with body size, and was significant mainly during the growth later period. This study provides the first evidence linking variation to the $m i R-1757$ gene and economic traits in chicken.

Our results are consistent with those of previous studies demonstrating that SNPs within miRNAs corresponding sequence are likely to result in phenotypic differences, affecting production traits. A T/C SNP located in the $m i R-27 a$ gene precursor was reported to affect litter size between different genotypes (Lei et al., 2011). A point mutation within murine miR-717 affected fat deposition (Kunej et al., 2010). Another previous study suggested that the rs16681031 SNP in the miR-1658* gene plays an important role in the formation of some phenotypes in chicken (Georges et al., 2007). For the SNP rs15505339, which is located in the loop of the pre-mir-1757, our predicted results regarding the most stable secondary structure of the wild-type and mutated sequence revealed that free-energy values and secondary structure were altered. Naturally occurring SNPs can impair or enhance miRNA processing as well as alter processing sites. Related studies have suggested that a mutation causing structural change in a crucial region of an miRNA can affect the maturation and processing of miRNA (Duan et 
al., 2007; Jazdzewski et al., 2008). A single mutation in pre-miR-155 created a mismatch near the 3 '-end of miR-155, leading to a shift in strand selection, thereby fine-tuning the targets and resulting in a butterfly effect on global gene expression (Lee et al., 2011). Single-base changes in precursor elements or mature miRNA sequences may contribute to the evolution of new miRNAs by altering their biological functions (Sun et al., 2009).

Our results showed that the effect of mutation on body size was predominant in later developmental stages. Quantitative trait loci (QTL) affecting body weights on chromosome 4 have been reported in chicken and were related to growth traits (Podisi et al., 2013). It was reported that the QTL correlated with 12-week body weight on chromosomes 1, 4, and 27 were the similar locations as carcass weight QTL in a related broiler research (Zhou et al., 2006). miR-1757 is also located on chromosome 4, and may be linked with the causative mutation or the QTL controlling growth traits in chickens. Real-time RT-PCR and microarray experiments revealed that numerous miRNAs are expressed in a spatiotemporal-specific manner in farm animals (Ambros, 2004).

Detection of the target genes of miRNAs is widely thought to be important for understanding the role of miRNAs (Watanabe et al., 2007). Functional pattern analysis (GO) for the conserved target (170 transcripts) of miRNA-1757 showed that most of these genes in the GO categories were related to transcription factor binding, cellular process, regulation of biological process, metabolic process, multicellular organismal process, and developmental process. Using the mRNA target gene prediction database and based on bioinformatic analyses, $m i R$ 1757 may be involved in regulating growth-related processes, which was in accord with our association analysis results. The host gene SLC25A43, which is involved in the cell cycle, metabolism, and cell proliferation, may also be related to the regulation function of miR-1757. These results may help us better understand the role of miRNA-1757.

This study revealed that rs 15505339 located in the terminal loop of pre-mir-1757 was significantly associated with carcass traits and body size index, and its effects mainly appeared during the later growth period. Our data provided a basis for the further functional studies. However, further studies are required to validate the genetic effects of the miR-1757 polymorphism on chicken economic traits.

\section{Conflicts of interest}

The authors declare no conflict of interest.

\section{ACKNOWLEDGMENTS}

Research supported by the National Natural Science Foundation of China (\#31201795), the Earmarked Fund for Modern Agro-Industry Technology Research System (\#CARS41-K04), the Science and Agricultural Research Outstanding Talents and Innovation Team of Ministry of Agriculture of China, and the 53rd Postdoctoral Funding (\#2013M531675).

\section{REFERENCES}

Ambros V (2004). The functions of animal microRNAs. Nature 431: 350-355.

Cerezo M, Černý V, Carracedo Á and Salas A (2009). Applications of MALDI-TOF MS to large-scale human mtDNA population-based studies. Electrophoresis 30: 3665-3673. 
Duan R, Pak C and Jin P (2007). Single nucleotide polymorphism associated with mature miR-125a alters the processing of pri-miRNA. Hum. Mol. Genet. 16: 1124-1131.

Ferreira DM, Afonso MB, Rodrigues PM, Simão A, et al. (2014). c-Jun N-terminal kinase 1/c-Jun activation of the p53/ microRNA 34a/sirtuin 1 pathway contributes to apoptosis induced by deoxycholic acid in rat liver. Mol. Cell Biol. 34: $1100-1120$.

Gao X, Qiao Y, Han D, Zhang Y, et al. (2012). Enemy or partner: relationship between intronic microRNAs and their host genes. IUBMB Life 64: 835-840.

Georges M, Coppieters W and Charlier C (2007). Polymorphic miRNA-mediated gene regulation: contribution to phenotypic variation and disease. Curr. Opin. Genet. Dev. 17: 166-176.

Gong J, Tong Y, Zhang HM, Wang K, et al. (2012). Genome-wide identification of SNPs in microRNA genes and the SNP effects on microRNA target binding and biogenesis. Hum. Mutat. 33: 254-263.

Han RL, Wei Y, Kang XT, Chen H, et al. (2012). Novel SNPs in the PRDM16 gene and their associations with performance traits in chickens. Mol. Biol. Rep. 39: 3153-3160.

Hou X, Tang Z, Liu H, Wang N, et al. (2012). Discovery of MicroRNAs associated with myogenesis by deep sequencing of serial developmental skeletal muscles in pigs. PloS One 7: e52123.

Jazdzewski K, Murray EL, Franssila K, Jarzab B, et al. (2008). Common SNP in pre-miR-146a decreases mature miR expression and predisposes to papillary thyroid carcinoma. Proc. Natl. Acad. Sci. U. S. A. 105: 7269-7274.

Kunej T, Skok DJ, Horvat S, Dovc P, et al. (2010). The glypican 3-hosted murine mir717 gene: sequence conservation, seed region polymorphisms and putative targets. Int. J. Biol. Sci. 6: 769-772.

Lee HC, Yang CW, Chen CY and Au LC (2011). Single point mutation of microRNA may cause butterfly effect on alteration of global gene expression. Biochem. Biophys. Res. Commun. 404: 1065-1069.

Lee JS, Kim JM, Lim KS, Hong JS, et al. (2013). Effects of polymorphisms in the porcine microRNA MIR206/MIR133B cluster on muscle fiber and meat quality traits. Anim. Genet. 44: 101-106.

Lei B, Gao S, Luo L, Xia X, et al. (2011). A SNP in the miR-27a gene is associated with litter size in pigs. Mol. Biol. Rep. 38: 3725-3729.

Li H, Sun GR, Lv SJ, Wei Y, et al. (2012). Association study of polymorphisms inside the miR-1657 seed region with chicken growth and meat traits. Br. Poult. Sci. 53: 770-776.

Li H, Sun GR, Tian YD, Han RL, et al. (2013). MicroRNAs-1614-3p gene seed region polymorphisms and association analysis with chicken production traits. J. Appl. Genet. 54: 209-213.

Liao WT, Ye YP, Zhang NJ, Li TT, et al. (2014). MicroRNA-30b functions as a tumour suppressor in human colorectal cancer by targeting KRAS, PIK3CD and BCL2. J. Pathol. 232: 415-427.

Lindqvist BM, Farkas SA, Wingren S and Nilsson TK (2012). DNA methylation pattern of the SLC25A43 gene in breast cancer. Epigenetics 7: 300-306.

Locke J, da Silva Xavier G, Dawe H, Rutter G, et al. (2014). Increased expression of miR-187 in human islets from individuals with type 2 diabetes is associated with reduced glucose-stimulated insulin secretion. Diabetologia 57: 122-128.

Mei J, Yue HM, Li Z, Chen B, et al. (2014). C1q-like factor, target of miR-430, regulates primordial germ cell development in early embryos of Carassius auratus. Int. J. Biol. Sci. 10: 15-24.

Mendisco F, Keyser C, Hollard C, Seldes V, et al. (2011). Application of the iPLEXTM Gold SNP genotyping method for the analysis of Amerindian ancient DNA samples: Benefits for ancient population studies. Electrophoresis 32: 386-393.

Podisi BK, Knott SA, Burt DW and Hocking PM (2013). Comparative analysis of quantitative trait loci for body weight, growth rate and growth curve parameters from 3 to 72 weeks of age in female chickens of a broiler-layer cross. $B M C$ Genet. 14:22.

Sun G, Yan J, Noltner K, Feng J, et al. (2009). SNPs in human miRNA genes affect biogenesis and function. RNA 15: 1640-1651.

Tang Z, Liang R, Zhao S, Wang R, et al. (2014). CNN3 is regulated by microRNA-1 during muscle development in pigs. Int. J. Biol. Sci. 10: 377-385.

Thorleifsson G, Walters GB, Hewitt AW, Masson G, et al. (2010). Common variants near CAV1 and CAV2 are associated with primary open-angle glaucoma. Nat. Genet. 42: 906-909.

Tina E, Lindqvist BM, Gabrielson M, Lubovac Z, et al. (2012). The mitochondrial transporter SLC25A43 is frequently deleted and may influence cell proliferation in HER2-positive breast tumors. BMC Cancer 12: 350.

Wang X, Gu Z and Jiang H (2013). MicroRNAs in farm animals. Animal 7: 1567-1575.

Watanabe Y, Tomita M and Kanai A (2007). Computational methods for microRNA target prediction. Methods Enzymol. 427: 65-86. 
Zhou H, Deeb N, Evock-Clover CM, Ashwell CM, et al. (2006). Genome-wide linkage analysis to identify chromosomal regions affecting phenotypic traits in the chicken. II. Growth and average daily gain. Poult. Sci. 85: 1700-1711.

Zorc M, Skok DJ, Godnic I, Calin GA, et al. (2012). Catalog of microRNA seed polymorphisms in vertebrates. PloS One 7: e30737.

Zuker M (2003). Mfold web server for nucleic acid folding and hybridization prediction. Nucleic Acids Res. 31: 34063415. 